\title{
ANALISIS PENGARUH PROMOSI, KUALITAS PRODUK DAN BRAND IMAGE MATIC HONDA TERHADAP KEPUTUSAN PEMBELIAN SERTA DAMPAKNYA TERHADAP LOYALITAS PELANGGAN
}

\author{
(Studi Kasus Pengguna Sepeda Motor Matic Honda Beat (KOTA BOGOR)) \\ Oleh : \\ Ahmad Wawan Setiawansah \\ Jurusan Manajemen Pemasaran \\ Email : ahmadwawan130@gmail.com
}

\begin{abstract}
ABSTRAK
Tujuan penelitian ini untuk menganalisis Pengaruh Promosi, Kualitas Produk dan Brand Image terhadap Keputusan Pembelian serta dampaknya terhadap Loyalitas Pelanggan (Studi Kasus Pengguna Sepeda Motor Matic Honda Beat (KOTA BOGOR)). Promosi, Kualitas Produk dan Brand Image dapat menjadi faktor pendukung bagi konsumen untuk meningkatkan Keputusan Pembelian konsumen serta dampaknya terhadap Loyalitas.

Tujuan Penelitian ini adalah (1). Pengaruh Promosi Terhadap Keputusan Pembelian (2) Pengaruh Promosi Terhadap Loyalitas (3) Pengaruh Kualitas produkTerhadap Keputusan Pembelian (4).Pengaruh Kualitas ProdukTerhadap Loyalitas (5).Pengaruh Brand ImageTerhadap Keputusan Pembelian (6).Pengaruh Brand ImageTerhadap Loyalitas (7).Pengaruh Keputusan Pembelian terhadap Loyalitas jumlah responden adalah 100 responden yang diambil dari masyrakat dikota bogor yang menggunakan Honda Beat Pop.

Diolah dengan SPSS versi 22, hasil penelitian adalah (1) Promosi memiliki pengaruh yang positif dan signifikan secara partial terhadap keputusan Pembelian sebesar 3,631. (2) Kualitas produk memiliki pengaruh yang positif dan signifikan secara partial terhadap keputusan Pembelian sebesar 2,182. (3) Brand Image memiliki pengaruh yang positif dan signifikan secara partial terhadap keputusan Pembelian sebesar 3,950. (4) Promosi memiliki pengaruh positif dan signifikan terhadap Loyalitas secara Parsial sebesar 2,635. (5) Kualitas Produk mempunyai hubungan yang positif dan signifikan yang signifikan secara partial terhadap Loyalitas sebesar 1.779. (6) Brand Image memiliki pengaruh positif dan tidak signifikan terhadap Loyalitas sebesar 0,948 (7)Keputusan Pembelian berpengaruh positif namun tidak signifikan terhadap Loyalitas secara partial sebesar 1,826 . (8) Uji Path Analisis Jalur $1 \quad Y=0,337 X 1+0,199 X 2+e$ dan jalur $2 \quad Z=0,324 X 1+0,207 X 2+0,132 X 3+0,232 Y+e$ uji auto korelasinya 1,579 dengan nilai R-Square sebesar $71,4 \%$ sedangkan sisanya dijelaskan oleh variabel lain.
\end{abstract}

Kata kunci : Promosi, Kualitas Produk, Brand Image, Keputusan Pembelian dan Loyalitas 


\section{PENDAHULUAN}

Seiring dengan perkembangan zaman serta tuntutan mobilitas yang tinggi kendaraan merupakan suatu alternative yang baik untuk mendukung aktivitas tersebut.Akan tetapi akhirakhir ini di Kota Bogor sering terjadi kemacetan lalu lintas yang bisa menghambat aktivitas tersebut. Oleh karena itu masyarakat membutuhkan solusi yang tepat untuk mengurai kemacetan tersebut berupa mode transportasi yang mudah, murah, simple, serta dapat menerobos kemacetan Kota Bogor dengan cepat.

Sepeda motor adalah salah satu alat transportasi yang digunakan untuk memudahkan aktivitas sehari-sehari. Maka dari itu banyak masyarakat atau konsumen yang lebih memilih menggunakan sepeda motor dibanding menggunakan mobil atau alat transportasi lainnya. Sepeda motor dianggap lebih praktis dan lebih mudah menerjang kemacetan. Honda Beat Pop terbaru resmi dipasarkan dengan sejumlah pembaruan. Bukan hanya tampilan berbeda, tapi fitur baru juga dibenamkan. Menariknya, harga Beat Pop tidak ada kenaikan. Dipasarkan mulai Rp 14,725 juta - Rp 15,425 juta, tergantung varian. Pembaruan Beat Pop juga menghadirkan optimisme tersendiri Honda berharap penjualan skutik ini bisa sebaik keluarga Beat lain: Sporty dan Street. Menurut data Asosiasi Industri Sepeda Motor Indonesia (AISI), distribusi skutik ini merupakan yang terburuk, hanya 2.524 unit pada September 2017. Sementara di periode sama, Beat Sporty laku 171.391 unit dan Beat Street 20.559 unit.

Dapat dilihat dari penjualan diatas Honda meluncurkan produk terbaru dengan harga yang lebih terjangkau dari keseluruhan penjualan honda matic beat spoty, beat street, dan hanya beat pop tidak terlalu laris dipasarannya. Bagi pelanggan ekuitas merek dapat memberikan nilai dalam memperkuat interpretasi proses informasi, memupuk percaya diri dalam pembelian, serta meningkatkan pencapaian kepuasan (Meliana, S., \& Setiawan, B., 2013). Nilai ekuitas merek bagi pemasar atau perusahaan dapat mempertinggi keberhasilan program pemasaran dalam memikat konsumen baru atau merangkul konsumen lama (Setiawan, B., 2018).

Hal ini dmungkinkan karena dengan merek yang telah dikenal maka promosi yang dilakukan akan lebih efektif. Dan perlu diketahui bahwa sebuah pemasaran tidak terlepas dari Marketing mix yaitu berupa Product, price, promotion, place karena 4 komponen itulah yang merupakan alat yang digunakan perusahaan dalam mencapai tujuannya, yaitu membentuk karakteristik barang dan jasa yang di tawarkan kepada pelanggan (Setiawan, B., 2010). 


\section{Identifikasi Masalah}

Berdasarkan uraian diatas penulis merumuskan permasalahan yaitu mengenai apa yang menjadi penyebab motor matic merek Honda Beat pop banyak digunakan oleh para pengguna motor matic, penulis menduga apakah hal tersebut disebabkan atau dipengaruhi oleh iklan, brand image (citra merek), dan kualitas produk. Sehingga penulis merumuskan pokok permasalahan yaitu:

1. Bagaimana pengaruh Promosi secara langsung terhadap Keputusan Pembelian?

2. Bagaimana pengaruh Promosi secara langsung terhadap Loyalitas ?

3. Bagaimana pengaruh Kualitas Produk secara langsung terhadap Keputusan Pembelian?

4. Bagaimana pengaruh Kualitas Produk secara langsung terhadap Loyalitas ?

5. Bagaimana pengaruh Brand Image secara langsung terhadap Keputusan Pembelian?

6. Bagaimana pengaruh Brand Image secara langsung terhadap Loyalitas ?

7. Bagaimana pengaruh Keputusan Pembelian secara langsung terhadap Loyalitas ?

\section{TINJAUAN PUSTAKA}

Berikut ini akan dikemukakan definisi menurut para ahli. Untuk mendapatkan gambaran mengenai Promosi menurut Kotler dan Armstrong (2012), "Promotion means activities that communicate the merits of the product and persuade target customers to buy it", artinya promosi merupakan kegiatan yang mengomunikasikan manfaat dari sebuah produk dan membujuk target konsumen untuk membeli produk tersebut.

Kualitas Produk Menurut Kotler dan Keller (2012), kualitas produk merupakan kemampuan suatu barang untuk memberikan hasil atau kinerja yang sesuai bahkan melebihi dari apa yang diinginkan pelanggan.

Brand Image menurut Kotler dan Keller (2012) mendefinisikan brand image sebagai sekumpulan persepsi dan kepercayaan yang dimiliki oleh konsumen terhadap suatu brand yang direfleksikan melalui asosiasi-asosiasi yang ada dalam ingatan konsumen.

Keputusan pembelian menurut Keller (2012) adalah keputusan meneruskan atau tidak meneruskan pembelian. Menurut Kotler (2009) keputusan membeli yaitu beberapa tahapan yang dilakukan oleh konsumen sebelum melakukan keputusan pembelian suatu produk

Loyalitas menurut Fandy Tjiptono (2011) mengatakan bahwa:"Loyalitas pelanggan sebagai komitmen pelanggan terhadap suatu merek, toko, pemasok berdasarkan sikap yang sangat positif tercermin dalam pembelian ulang yang konsisten". 


\section{METODOLOGI PENELITIAN}

Metodologi penelitian yang digunakan dalam penelitian ini adalah metode deskriptif dan metode kuantitatif.

Sumber data yang digunakan dalam penelitian ini adalah data primer dan data sekunder, data primer penelitian ini antara lain adalah dta yang diperoleh dari hasil kuesioner yang dibagikan kepada konsumen (Setiawan, B., 2015). Data sekunder dalam penelitian ini berupa studi kepustakaan, penelitian terdahulu dan literatur-literatur yang berkaitan dengan Promosi, Kualitas Produk, Brand Image, Keputusan Pembelian, dan Loyalitas.

Metode pengumpulan data yang dilakukan dalam Penelitian ini adalah: (1) Observasi, (2) Wawancara, (3) Kuesioner.

Berkaitan dengan Penelitian ini, penulis membuat penelitian dngan menggunakan analisis Regresi Berganda. Dalam pengelolaan data dan kuesioner digunakan alat aalisis yaitu Software SPSS Statictic 22 dalam mencari tanggapan responden mengenai Promosi, Kualitas Produk, Brand Image dan Keputusan Pembelian serta Loyalitas

\section{HASIL DAN PEMBAHASAN}

Berdasarkan hasil dan pengolahan data kuesioner menggunakan program SPSS yang telah di lakukan peneliti, maka pembahasan terhadap hipotesis penelitian adalah yang menyatakan :

\section{Hubungan Promosi dengan Keputusan Pembelian}

Diperoleh nilai T hitung sebesar 3,631 lebih besar dari T table Dengan demikian hipotesis satu diterima, $\mathrm{H} 0$ ditolak dan $\mathrm{H} 1$ diterima. Hal ini berarti ada pengaruh positif dan signifikan antara Promosi dengan Keputusan Pembelian.

\section{Hubungan Kualitas Produk dengan Keputusan Pembelian}

Diperoleh nilai T hitung sebesar 2,182 lebih besar dari T tabel. Dengan demikian hipotesis dua diterima, $\mathrm{H} 0$ ditolak dan $\mathrm{H} 2$ diterima hal ini berarti ada pengaruh positif dan signifikan antara Kualitas Produk dengan Keputusan Pembelian.

\section{Hubungan Brand Image dengan Keputusan Pembelian}

Diperoleh nilai T hitung sebesar 3,950 lebih besar dari T tabel. Dengan demikian hipotesis tiga diterima, $\mathrm{H} 0$ ditolak dan $\mathrm{H} 3$ diterima hal ini berarti ada pengaruh positif dan signifikan antara Brand Image dengan Keputusan Pembelian.

\section{Hubungan Promosi dengan Loyalitas}


Diperoleh nilai T hitung sebesar 2,635 lebih besar dari T tabel. Dengan demikian hipotesis empat diterima, $\mathrm{H} 0$ ditolak dan $\mathrm{H} 4$ diterima hal ini berarti ada pengaruh positif dan signifikan antara Promosi dengan Loyalitas

\section{Hubungan Kualitas Produk dengan Loyalitas}

Diperoleh nilai T hitung sebesar 1,779 lebih besar dari T tabel. Dengan demikian hipotesis lima diterima, $\mathrm{H} 0$ ditolak dan $\mathrm{H} 5$ diterima hal ini berarti ada pengaruh positif dan signifikan antara Kualitas Produk dengan Loyalitas

\section{Hubungan Brand Image dengan Loyalitas}

Diperoleh nilai T hitung sebesar 0,948 lebih besar dari T tabel. Dengan demikian hipotesis enam diterima, $\mathrm{HO}$ ditolak dan $\mathrm{H} 6$ diterima hal ini berarti ada pengaruh positif dan signifikan antara Brand Image dengan Loyalitas

\section{Hubungan Keputusan Pembelian dengan Loyalitas}

Diperoleh nilai T hitung sebesar 2,635 lebih besar dari T tabel. Dengan demikian hipotesis 7 ditolak, $\mathrm{H} 0$ diterima dan $\mathrm{H} 7$ ditolak hal ini berarti tidak ada pengaruh positif dan signifikan antara Keputusan Pembelian dengan Loyalitas

\section{KESIMPULAN}

Berdasarkan hasil analisis dan pembahasan yang telah diuraikan sebelumnya, maka dapat ditarik beberapa kesimpulan dari keseluruhan hasil penelitian yaitu sebagai berikut :

1. Promosi memiliki pengaruh yang positif dan signifikan terhadap Keputusan Pembelian produk Honda Beat. Pop Berdasarkan hasil pengujian parsial yang diperoleh atas variabel Promosi maka T - hitung lebih besar dari T - tabel, pada konsumen Honda Beat Pop dikalangan Masyarakat Kota Bogor.

2. Kualitas Produk memiliki pengaruh yang positif dan signifikan terhadap Keputusan Pembelian produk Honda Beat. Pop Berdasarkan hasil pengujian parsial yang diperoleh atas variabel Kualitas Produk aka T - hitung lebih besar dari $\mathrm{T}$ - tabel, pada konsumen Honda Beat Pop dikalangan Masyarakat Kota Bogor.

3. Brand image memiliki pengaruh yang positif dan signifikan terhadap Keputusan Pembelian produk Honda Beat. Pop Berdasarkan hasil pengujian parsial yang diperoleh atas variabel Brand Image maka T - hitung lebih besar dari T - tabel, pada konsumen Honda Beat Pop dikalangan Masyarakat Kota Bogor.

4. Promosi memiliki pengaruh yang positif dan signifikan terhadap Loyalitas produk Honda Beat. Pop Berdasarkan hasil pengujian parsial yang diperoleh atas variabel Promosi 
maka $\mathrm{T}$ - hitung lebih besar dari T - tabel, pada konsumen Honda Beat Pop dikalangan Masyarakat Kota Bogor.

5. Kualtas Produk memiliki pengaruh yang positif dan signifikan terhadap Loyalitas produk Honda Beat. Pop Berdasarkan hasil pengujian parsial yang diperoleh atas variabel Promosi maka T - hitung lebih besar dari T - tabel, pada konsumen Honda Beat Pop dikalangan Masyarakat Kota Bogor.

6. Brand image memiliki pengaruh yang positif dan signifikan terhadap Loyalitas produk Honda Beat. Pop Berdasarkan hasil pengujian parsial yang diperoleh atas variabel Promosi maka T - hitung lebih besar dari T - tabel, pada konsumen Honda Beat Pop dikalangan Masyarakat Kota Bogor.

7. Keputusan Pembelian memiliki pengaruh yang positif dan signifikan terhadap Loyalitas produk Honda Beat. Pop Berdasarkan hasil pengujian parsial yang diperoleh atas variabel Keputusan Pembelian maka $T$ - hitung lebih besar dari $T$ - tabel, pada konsumen Honda Beat Pop dikalangan Masyarakat Kota Bogor.

\section{SARAN}

Berdasarkan hasil kesimpulan yang telah diuraikan maka dapat diberikan saran-saran yang dapat dijadikan sebagai bahan pertimbangan bagi perusahaan, yaitu :

1. Berdasarkan hasil perhitungan variabel Promosi nilai pengaruh sebesar 3,631 terhadap Keputusan Pembelian Honda Beat Pop, maka dari itu perusahaan harus mempertahankan Promosi dan juga menambah promosi baru agar bisa lebih menarik Konsumen agar meningkat Pembeliannya

2. Berdasarkan hasil perhitungan variabel Kualitas Produk nilai pengaruh sebesar 2,182 terhadap Keputusan Pembelian Honda Beat Pop, maka dari itu perusahaan harus mempertahankan Kualitas Produk honda Beat Pop agar bisa lebih menarik Konsumen agar meningkat Pembeliannya

3. Berdasarkan hasil perhitungan variabel Brand image nilai pengaruh sebesar 3,950 terhadap Keputusan Pembelian Honda Beat Pop, maka dari itu perusahaan harus mempertahankan Citra Merek Perusahaan Honda agar bisa lebih menarik Konsumen agar meningkat Pembeliannya

4. Berdasarkan hasil perhitungan variabel Promosi nilai pengaruh sebesar 2,635 terhadap Loyalitas Honda Beat Pop, maka dari itu perusahaan harus mempertahankan Promosi 
dan juga menambah promosi baru agar bisa lebih menarik Konsumen agar bisa meningkatkan loyalitas konsumen terhadap perusahaan

5. Berdasarkan hasil perhitungan variabel Kualitas Produk nilai pengaruh sebesar 1,779 terhadap Loyalitas Honda Beat Pop, maka dari itu perusahaan harus mempertahankan Kualitas produk Honda Beat Pop agar bisa meningkatkan loyalitas konsumen terhadap perusahaan

6. Berdasarkan hasil perhitungan variabel Brand Image nilai pengaruh sebesar 0,948 terhadap Loyalitas Honda Beat Pop, maka dari itu perusahaan harus mempertahankan citra perusahaan Honda Beat Pop agar bisa meningkatkan loyalitas konsumen terhadap perusahaan

7. Berdasarkan hasil perhitungan Variabel Keputusan Pembelian nilai pengaruh sebesar 59.198 terhadap Loyalitas Honda Beat Pop, maka dari itu perusahaan harus mempertahankan Pembelian Honda Beat Pop agar bisa meningkatkan loyalitas konsumen terhadap perusahaan

\section{DAFTAR PUSTAKA}

\section{BUKU-BUKU}

Alfian, B. 2012. Pengaruh Citra Merek (Brand Image) Terhadap pengambilan Keputsan Pembelian Mobil Toyota Kidjang Inova Pada PT. Hadji Kalla Cabang Polma Makasar: Skripsi Universitas Hasanuddin

Agung, Bhuono,. "Strategi Jitu dalam memilih metode statistic penelitian dengan SPSS", CV. Andi Offset, Yogyakarta 2005

Assauri, Sofjan. 2013. Manajemen Pemasaran. Jakarta : Rajawali pers

Buchory, Herry Achmad \& Djaslim Saladin. 2010. Manajemen Pemasaran.

Daryanto. 2011. Manajemen Pemasaran. Bndung: PT Sarana Tutorial Nurani Sejahtera

Ghozali, Imam. 2009. Aplikasi Analisis Multivariate dengan Program SPSS. Semarang. Universitas Dipenogoro.

Ghozali, Imam. 2011. Aplikasi Analisis Multivariate dengan Program SPSS. Semarang. Universitas Dipenogoro. 
Ghozali, Imam. 2013. Aplikasi Analisis Multivariate dengan Program SPSS. Semarang. Universitas Dipenogoro.

Giffin,Jill. "Customer loyality: Menumbuhkan dan mempertahankan kesetiaan pelanggan". Penerbit Erlangga, Jakarta,2005.

Hermawan. Agus. 2012. Komunikasi Pemasaran. Jakarta. Erlangga

Hurriyati, Ratih. 2010. Bauran Pemasaran dan Loyalitas Konsumen. Bandung: ALFABETHA.

Kertajaya, Hermawan. 2006. Seri Hermawan Kertajaya on Marketing Mix, Jakarta: PT. Gramedia Pustaka Utama

Keller, Kevin Lane. 2013. Strategic Brand Management. Fourth Edition. Harlow : Pearson Education Limitied.

Kotler, Philip dan Keller, Kevin Lane,. 2007, Manajemen Pemasaran, Edisi $12 \quad$ Jilid 1 dialih bahasakan oleh Benjamin Molan, Jakarta : PT. Indeks.

Kotler, Philip dan Keller, Kevin Lane. 2012. Manajemen Pemasaran. Edisi $12 . \quad$ Jakarta: Erlangga.

Kotler, Philip and Armstrong, Gray. 2012. Prinsip-prinsip Pemasaran. Edisi $13 . \quad$ Jilid 1. Jakarta: Erlangga.

Kotler, Philip and Armstrong Gray 2012. Prinsip-prinsip Pemasaran. Edisi 12. Jilid Terjemahan Bob Sabrana. Jakarta: Erlangga

Kotler, Philip, Amstrong Gary. 2013. Prinsip-prinsip Pemasaran, Edisi ke 12. Penerbit Erlangga.

Kuncoro, Mudrajad 2010, Masalah, Kebijakan, dan Politik, Ekonomika Pembangunan. Penerbit Erlangga. Jakarta.

Meliana, S., \& Setiawan, B. (2013). Pengaruh Kualitas Pelayanan dan Kepercayaan Konsumen Terhadap Keputusan Pembelian. IImiah Manajemen Kesatuan, 1, 247-254.

Sekaran, Uma. 2006 Metodelogi Penelitian untuk bisnis, Buku 2 Edisi 4. Jakarta: SalembaEmpat 
Stanton,William J, 1978, Fundamental of Marketing . New York: McGraw Hill Book Company Inc.

Setiawan, B., \& Rabuani, C. (2019). Pengaruh Iklan dan Endorser terhadap Brand Awareness serta Dampaknya pada Keputusan Pembelian. Jurnal Riset, 1(1), 001-015. https://doi.org/10.35212/277621

Setiawan, B. (2018, April 7). A Critical Review of the Business Agility Literature in the Advancement of Information and Communication Technology. https://doi.org/10.31227/osf.io/x4kwi

Setiawan, B. (2015). Teknik Praktis Analisis Data Penelitian Sosial dan Bisnis dengan SPSS. Penerbit Andi, Yogyakarta.

Setiawan, B. (2010). Strategi Pengembangan Usaha Kerajinan Bambu di Wilayah Kampung Pajeleran Sukahati Kecamatan Cibinong Kabupaten Bogor. Jurnal Manajemen dan Organisasi, 1(2), 135-147.

Sugiyono, 2014. Metode Penelitian Kuantitatif, Kualitatif, dan R\&D. Cetakan Ke 18. Bandung. CV Alfabeta

Sujarweni, V Wiratna. 2015. Metode Penelitian Bisnis dan Ekonomi. Yogyakarta PT. Pustaka Baru Press.

Tjiptono, Fandy. 2010, Strategi Pemasaran, Edisi 2, Andi Offset, Yogyakarta.

Tjiptono, Fandy. 2012, Pemasaran Strategik, Andi, Yogyakarta,

\section{JURNAL DAN SKRIPSI}

Agyekum, Crentsil Kofi. 2015. Consumer Perception of Product Quality, China Journal Of Management and Economics Department. Volume 3 No. Halaman 25. Beijing University of Tech China.

Andromedha, Nugroho wisnu. 2013. "Analisis pengaruh efektivitas iklan terhadap keputusan pembelian sepeda motor matik yamaha di semarang." Skripsi, Fakultas Ekonomi \& Bisnis. 
Basrah Saidani. 2013. Pengaruh Kualitas Produk dan Desain ProdukTerhadap Keputusan Pembelian Sepatu Olahraga Futsal Adidas Di Wilayah Jakarta Timur. Jakarta. Universitas Negri Jakarta

Eva Inayah Luftiani. 2016. Pengaruh Persepsi Kualitas, Citra Merek dan Persepsi Harga Terhadap Minat Beli Pada Produk Merek Toko (Studi Kasus pada Konsumen Bio Organik di Supermarket SuperIndo Yogyakarta). Yogyakarta. Universitas Negri Yogyakarta

El Junusi, Rahman. 2009. Pengaruh Atribut Produk Islam, Komitmen Agama, Kualitas Jasa Dan Kepercayaan Terhadap Kepuasan Dan Loyalitas Nasabah Bank Syriah (Pada Bank Muamalat Kota Semarang). Surakarta : The 9th Annual Conference On Islamic Studies (Acis)

Fuad Asshiddiqie. 2012. Analisi Pengaruh Harga, Desain Produk Dan Citra Merek Terhadap Keputusan Pembelian (Studi Kasus pada Produk Crooz di Distro Ultraa Store Semarang).. Semarang. Universitas Diponegoro

Gloria Tengor, Lotje Kawet dan Sjendry Loindong. 2016. Pengaruh Merek, Desain Dan Kualitas Produk Terhadap Keputusan Pembelian Iphone Studi Kasus Pada Mahasiswa STIE Eben Haezar Manado. Manado. Universitas Sam Ratulangi

Kurniawan Hery."Analisis Faktor-faktor Yang Mempengaruhi Konsumen Dalam Pengambilan Keputusan Pembelian Produk Mie Instant Merek Sedaap (Studi Pada Mahasiswa Fakultas Ekonomi Universitas merdeka malang". 2006

Lingga Binangkitiasari. 2018. Pengaruh Kesadaran Merek, Asosiasi Merek, Persepsi Kualitas dan Loyalitas Terhadap Keputusan pembelian dan Loyalitas (Studi Kasus Pada Konsumen Garuda Indonesia Di kota Bogor). Bogor. STIE Kesatuan Bogor

Michael K. Scott. 2011. Perspective: Luchs and The Emergence of Product Design as a Field of Marketing Inquiry Swan. Journal Product Development \& Management Association. J PROD INNOV MANAG 2011;28:327-345 
Merry Yana Sari. 2017. Pengaruh Persepsi Kualitas Produk Terhadap Keputusan Pembelian Pada Produk Hand And Body Lotion Vaseline Di Bandar Lampung. Lampung. Universitas Lampung

Pramono, Agil Aryo, 2011. "Analisis Pengaruh Elemen-Elemen Ekuitas Merek Terhadap Keputusan Pembelian pada Notebook Toshiba di Semarang", Skripsi Fakultas Ekonomi Universitas Diponegoro.

Pril Ranto, Dwi Wahyu, 2014 Pengaruh Harga, Desain Produk, Kualitas Produk Dan Citra Merek Terhadap Keputusan Pembelian Konsumen Pada Produk UKM Di Yogyakarta. Journal of marketing. Vol. 5, No.2,hal 206-2018

Rofiq, Ainun.,dkk. "Peranan Ekuitas Merek Terhadap Loyalitas Pelanggan pada Industri Telepon Seluler". FE Universitas Brawijaya, Malang, 2009

Saleh Thalib. 2017. Pengaruh Global Brand Image, Country Of Origins, Persepsi Kualitas Produk Terhadap Minat Beli Konsumen (Studi Kasus Sepatu Olahraga Nike di Kota Bogor). Bogor : Sekolah Tinggi Ilmu Ekonomi Kesatuan

Sharokk, Z. D., Sedghiani, J. S., dan Ghasemi, V., 2012., Analyzing The Influence Of Customer Attitude Toward Brand Extension On Attitude Toward Parent Brand, Interdisciplinary Journal Of Contemporary Research In Business, Vol. 3, No. 9, pp. 1133-1148.

Suryaningsih, Ika Barokah dan Hary Prayogo. 2011. Ekuitas Merek Produk Minuman Serbuk Buah Instan. Jurnal Bisnis dan Manajemen, 5(1), h: $67 \quad 91$.

\section{WEBSITE}

http://pertamax7.com/2019/02/21/data-aisi-januari-2019/ (diakses Pada tanggal 7 Mei 2019) https://www.maxmanroe.com/vid/marketing/pengertian-manajemen-pemasaran.html/ (diakses Pada tanggal 7 Mei 2019) 